\title{
Severe diabetes, age-dependent loss of adipose tissue, and mild growth deficiency in mice lacking Akt2/PKB $\beta$
}

\author{
Robert S. Garofalo, Stephen J. Orena, Kristina Rafidi, Anthony J. Torchia, Jeffrey L. Stock, \\ Audrey L. Hildebrandt, Timothy Coskran, Shawn C. Black, Dominique J. Brees, \\ Joan R. Wicks, John D. McNeish, and Kevin G. Coleman
}

Pfizer Global Research and Development, Groton, Connecticut, USA

The serine/threonine kinase Akt/PKB plays key roles in the regulation of cell growth, survival, and metabolism. It remains unclear, however, whether the functions of individual Akt/PKB isoforms are distinct. To investigate the function of $A k t 2 / \mathrm{PKB} \beta$, mice lacking this isoform were generated. Both male and female Akt2/PKB $\beta$-null mice exhibit mild growth deficiency and an age-dependent loss of adipose tissue or lipoatrophy, with all observed adipose depots dramatically reduced by 22 weeks of age. Akt $2 / \mathrm{PKB} \beta$-deficient mice are insulin resistant with elevated plasma triglycerides. In addition, Akt2/PKB $\beta$-deficient mice exhibit fed and fasting hyperglycemia, hyperinsulinemia, glucose intolerance, and impaired muscle glucose uptake. In males, insulin resistance progresses to a severe form of diabetes accompanied by pancreatic $\beta$ cell failure. In contrast, female Akt $2 / \mathrm{PKB} \beta-$ deficient mice remain mildly hyperglycemic and hyperinsulinemic until at least one year of age. Thus, Akt2/PKB $\beta$-deficient mice exhibit growth deficiency similar to that reported previously for mice lacking Akt $1 / \mathrm{PKB} \alpha$, indicating that both $\mathrm{Akt} 2 / \mathrm{PKB} \beta$ and $\mathrm{Akt} 1 / \mathrm{PKB} \alpha$ participate in the regulation of growth. The marked hyperglycemia and loss of pancreatic $\beta$ cells and adipose tissue in Akt $2 / \mathrm{PKB} \beta$-deficient mice suggest that $\mathrm{Akt} 2 / \mathrm{PKB} \beta$ plays critical roles in glucose metabolism and the development or maintenance of proper adipose tissue and islet mass for which other Akt/PKB isoforms are unable to fully compensate.

This article was published online in advance of the print edition. The date of publication is available from the JCI website, http://www.jci.org. J. Clin. Invest. 112:197-208 (2003). doi:10.1172/JCI200316885.

\section{Introduction}

The serine/threonine kinase Akt/PKB was first identified as an oncogene and as a kinase with properties resembling both PKA and $\mathrm{PKC}$ (hence $\mathrm{PKB})(1,2)$. There are three mammalian isoforms of this enzyme: Akt1 $(\mathrm{PKB} \alpha), \mathrm{Akt} 2(\mathrm{PKB} \beta)$, and Akt3 (PKB $\gamma)$. Akt1 shares $81 \%$ and $83 \%$ amino acid identity with Akt 2 and Akt3, respectively. Although the three isoforms show broad tissue distribution (3), Akt1 is the most ubiquitously expressed. Akt 2 is expressed at a lower level than Akt1 except in insulin-responsive tissues where it predominates $(4,5)$. Akt 3 is expressed at the lowest level

Received for publication September 11, 2002, and accepted in revised form May 6, 2003.

Address correspondence to: Robert S. Garofalo, Pfizer Global Research and Development, MS 8220-3082, Eastern Point Road, Groton, Connecticut 06357, USA.

Phone: (860) 441-1055; Fax: (860) 441-0548;

E-mail: robert_s_garofalo@groton.pfizer.com.

Joan R. Wicks' present address is: Pathology Associates, Frederick, Maryland, USA.

Conflict of interest: The authors have declared that no conflict of interest exists.

Nonstandard abbreviations used: computed tomography (CT); glucose 6-phosphatase (G6Pase); phosphoenolpyruvate carboxykinase (PEPCK); glycogen synthase (GS); GS homogenization buffer (HB); absence of reverse transcriptase (minus RT); G6P-independent synthase activity $\left(\mathrm{GS}_{\mathrm{i}}\right)$; knockout of insulin receptors in fat (FIRKO); knockout of insulin receptor in muscle (MIRKO); knockout of insulin receptor in liver (LIRKO); insulin receptor (IR); Zucker diabetic fatty (ZDF). except in testes and brain $(6,7)$. Preliminary analysis of the Akt1, Akt2, and Akt3 gene products suggest that the three isoforms have similar biochemical characteristics (8) and that phosphorylation of two sites is necessary for full activation of each isoform (9). Translocation of Akt to the plasma membrane through its pleckstrin homology domain is likely required for its activity (10), and constitutive targeting of Akt to the plasma membrane is sufficient to promote its activation $(11,12)$. Both the upstream activating kinases and the recruitment of Akt to the plasma membrane are dependent upon the products of PI3K (13). Some evidence suggests, however, that Akt isoforms are differentially activated in different insulin-responsive tissues following insulin stimulation (14). In particular, Akt2 is more abundant and more highly activated than Akt1 in adipocytes (14).

Akt is activated in response to many different growth factors, including insulin and IGF-1 (9). Akt is important for mediating the effects of these growth factors on the control of mammalian cell cycle progression and cell survival, as well as on the regulation of processes that influence growth, including protein synthesis and glucose metabolism. Akt regulates cell size in species as divergent as Drosophila (15) and mice (16, $17)$, indicating that its growth regulatory function is broadly conserved. Both the expression and translocation of glucose transporters in insulin-responsive cells $(18,19)$, as well as the activation of glycogen synthesis 
via inhibition of glycogen synthase kinase-3 $(20,21)$, are regulated by Akt. Thus, Akt plays a key role in the coordinated regulation of growth and metabolism by the insulin/IGF-signaling pathway. This close coordination reflects the well-conserved role of this pathway in modulating growth in response to environmental changes in nutrient availability (22).

Targeted disruption of individual Akt genes is being used to dissect the functions of Akt isoforms. Recently, analysis of mice lacking the genes encoding either Akt1 or Akt2 has suggested nonredundant functions for the two genes. Both Akt1-null and Akt2-null mice are viable, but Akt1-deficient mice exhibit a growth deficiency and normal glucose metabolism $(23,24)$, whereas Akt2-deficient mice exhibit insulin resistance and mild diabetes with no apparent difference in size (25). The viability and relative subtlety of these phenotypes suggest, however, that for many functions the three Akt isoforms are able to compensate for each other.

The data presented here on another line of Akt2-deficient mice confirm the major role of Akt2 in the regulation of glucose metabolism. The severe lipoatrophy or decrease in adipose tissue (26) in these Akt2-deficient mice, however, suggests an additional critical function for Akt 2 in the development or maintenance of proper adipose tissue mass. Lipoatrophy is associated with severe insulin resistance and diabetes (26) and might contribute to the observed diabetic phenotype of these mice. Furthermore, unlike the previously described Akt2-null mice (25), a compensatory increase in pancreatic islet mass and number is not observed, and a large percentage of male Akt2-null mice progress to a severe form of diabetes that includes $\beta$ cell failure by $5-8$ months of age. In addition, in contrast to a previous report (25), the Akt2-null mice described here exhibit a mild growth deficiency that persists throughout life. These data suggest that both Akt1 and Akt2 participate in the regulation of normal growth.

\section{Methods}

Construction of Akt2 targeting vector and Akt2-/- animal generation. Mouse genomic clones containing the Akt 2 locus were isolated from a DBA/1lacj genomic $\lambda$-phage library (Stratagene, La Jolla, California, USA) using a murine Akt2 partial cDNA fragment as a probe. A 6.3$\mathrm{kb} 5^{\prime}$ fragment and a 2-kb 3' fragment were cloned into pJNS2, a plasmid containing PGK-neo and PGKTK cassettes. The Akt 2 targeting vector was designed to replace $3.4-\mathrm{kb}$ of the genomic locus with the PGKneo cassette. Three exons corresponding to bp 788-1047 of the murine cDNA (U22445) are located within this 3.4-kb knockout region. DBA/1lacj ES cells were grown and transfected using protocols described previously (27). ES cell clones having undergone homologous recombination with the targeting vector were identified using a $1.0-\mathrm{kb}$ BamHI/XbaI $3^{\prime}$ probe located external to the targeting vector. Targeted ES cells were microinjected into C57BL/6 blastocysts using established techniques (28). Male chimeras were backcrossed to DBA/1lacJ females, and germline offspring were genotyped for the presence of a targeted Akt2 allele by PCR using genomic DNA isolated from tail biopsies. This method of germline transmission does not compromise the genetic background of the inbred strain (27). Brown coat color was used to identify germline offspring that are $100 \% \mathrm{DBA} / 1 \mathrm{lacJ}$ inbred genetic background. $A k t 2^{+/-}$animals were intercrossed, and offspring were genotyped using a tworeaction PCR method. One reaction amplifies a 190-bp fragment from a targeted allele using primers neo833F (5' GCAGGATCTCCTGTCATCTCACC $\left.3^{\prime}\right)$ and neo1023R ( $5^{\prime}$ GATGCTCTTCGTCCAGATCATCC $\left.3^{\prime}\right)$. The second reaction amplifies a 359-bp fragment from an endogenous allele using primers Akt2KO-178F (5' GAGGTAGAAACAAGAGAATCATGG $3^{\prime}$ ) and Akt2KO537R (5' GTTCGCACTGCTGTATGTTGC 3'), contained within the 3.4-kb knockout region. Notably, there are no reports of diabetes or obesity linked to the DBA/1lacJ strain, whereas the DBA/2 and related C57BL/KsJ strains (29) exhibit a genetic predisposition to $\beta$ cell failure that is evident when the $o b$ or $d b$ mutations are crossed onto these backgrounds (30, 31). The genetic differences between the DBA/2 and DBA/1 strains, however, are large enough that they should be regarded as different strains rather than substrains of the same strain (32). Thus the lace of a significant genetic relationship between the two DBA strains suggests that the phenotype observed in the DBA/1lacJ Akt2-null mice described here is unrelated to that observed in the DBA/2 strain.

Protein analysis. Whole $A k t^{+/+}$and $A k t^{-/-}$brains were homogenized in $10 \mathrm{vol}$ homogenization buffer $(50 \mathrm{mM}$ Tris, pH 8.0, $10 \mathrm{mM} \beta$-glycerophosphate, 5 mM EGTA, $50 \mathrm{mM} \mathrm{NaCl}, 10 \mathrm{mM}$ DTT, $1 \mu \mathrm{M}$ microcystin, $1 \mathrm{mM}$ $\mathrm{NaVO}_{4}, 1 \mathrm{mM}$ benzamidine, $1 \times$ Calbiochem protease inhibitor cocktail). The tissues were disrupted using a polytron, and cell debris was cleared by centrifugation at $17,000 \mathrm{~g}\left(10\right.$ minutes at $\left.4^{\circ} \mathrm{C}\right)$. Supernatants were recovered and protein concentration was determined by Bradford assay. Twenty-five micrograms of protein extract was analyzed by SDS-PAGE using a $4-12 \%$ NuPage gel in $1 \times$ Mops SDS running buffer (NP0050; Invitrogen Corp., San Diego, California, USA). Western blot analysis was performed according to manufacturer's instructions using anti-Akt1 (no. 06-558) and antiAkt2 (no. 06-606) Ab's from Upstate Biotechnology Inc. (Lake Placid, New York, USA).

Oral glucose-tolerance test and glucose measurements. Male and female wild-type and Akt2-null mice at 7 weeks of age were fasted overnight. A blood sample was collected from the retro-orbital sinus with a micropipette $(0.025 \mathrm{ml})$ immediately before administration of a glucose load ( $1 \mathrm{~g}$ glucose per kilogram of body weight) by oral gavage using a syringe equipped with a murine oral-feeding needle (20 gauge; Popper \& Sons Inc., New Hyde Park, New York, USA). Blood samples were taken at 30,60, and 120 minutes following glucose administration. Blood was immediately diluted into $100 \mu \mathrm{l}$ of 
$0.025 \%$ heparin in normal saline on ice. Red cells were pelleted by centrifugation at top speed in a Beckman Microfuge 12 for 2 minutes. Glucose was determined in the supernatants using the Roche/Hitachi 912 clinical chemistry analyzer (Roche Diagnostics Corp, Indianapolis, Indiana, USA).

Plasma insulin measurements. Insulin was measured in whole plasma or in samples prepared for glucose measurements (described above) by radioimmunoassay using the rat insulin RIA kit (RI-13K) or the sensitive rat insulin RIA kit (SRI-13K; Linco Research Inc., St. Charles, Missouri, USA).

Morphometric analysis of the pancreatic islets and adipose tissue. Pancreatic tissues and epididymal fat pads were fixed in formalin and embedded in paraffin, and sections were stained by hematoxylin and eosin. For pancreatic islets in each animal, the area of the whole section of pancreas and of 12 randomly selected islets in that section were measured using Image-Pro Plus image analysis software. The total numbers of islets per section were manually counted. The percentage of the surface area occupied by the islets compared with the total area of the pancreas section was calculated using the following formula: mean islet area $\times$ total number of islets $\times 100 /$ total area of the section. The mean number of islets per section of pancreas was calculated using the following formula: number of islets $\times 10^{6}$ per total area of the section. Data were analyzed using a three-factor ANOVA. The main categories were treatment group (control versus knockout), sex, and week of sacrifice ( 7 or 24 weeks). The model included the three two-way and the three-way interaction terms. Because the 24-week-old male islet area data had an appreciably smaller SD than all other factor combinations, the analysis was repeated using the log transformation. For adipose tissue, morphometric analysis was performed using Image-Pro analysis software. The number of adipocytes was determined in six randomly selected areas from the epididymal fat pads from 9week-old ( $n=3$ control; $n=6 \mathrm{Akt} 2$ null) and 11.7-weekold $(n=5$ control; $n=5 \mathrm{Akt} 2$ null) male mice.

Insulin and caspase-3 immunohistochemistry. Formalinfixed paraffin-embedded sections of pancreas were deparaffinized, rehydrated, and incubated with $3 \%$ hydrogen peroxide for 10 minutes in order to quench endogenous peroxidase activity. The sections were blocked with DAKO protein block (X0909; DAKO Corp., Carpinteria, California, USA) for 20 minutes. Each of the steps following the application of the primary $\mathrm{Ab}$ were preceded by a rinse in BioGenex wash buffer (HK583-5K; BioGenex Laboratories, San Ramon, California, USA). For insulin staining, the sections were then incubated with a guinea pig anti-insulin $\operatorname{IgG}$ (A0564; DAKO Corp.) diluted 1:1,000 for 1 hour at room temperature. For caspase-3 staining, the sections were incubated with a rabbit IgG (Cell Signalling Technology, Beverly, Massachusetts, USA) anti-cleaved caspase-3 (Asp175 clone) diluted 1:150 for 1 hour at room temperature. The anti-insulin primary $\mathrm{Ab}$ was followed by a 45 -minute incubation with a biotin-labeled goat anti-guinea pig IgG diluted at 1:150 (BA-7000; Vector Laboratories, Burlingame, California, USA). The anticaspase-3 primary Ab was followed by a 45 -minute incubation with a biotin-labeled goat anti-rabbit IgG diluted at 1:150 (Vector Laboratories). Finally, the sections were incubated with the Elite ABC Kit (PK-6100; Vector Laboratories) for 30 minutes, stained with a DAKO liquid 3,3-diaminobenzidine (K3468; DAKO Corp.) for 5 minutes according to the manufacturer's instructions, and counterstained with hematoxylin.

Micro-computed tomography scanning. Images were obtained using a commercially available micro-computed tomography (micro-CT) system (MicroCAT; ImTek Inc., Knoxville, Tennessee, USA) with a high-resolution charge coupled device/phosphor screen detector. The scanner consisted of a cylindrical-diameter/ long-field view of $50 \mathrm{~mm}$ by $50 \mathrm{~mm}$ with a spatial resolution of less than $50 \mu \mathrm{m}$. The $\mathrm{x}$-ray source was biased at $40 \mathrm{keV}$ with the anode current set to $400 \mu \mathrm{A}$. Anesthetized mice were placed on a radio-transparent mouse bed in a supine position, caudal end closest to the micro-CT with the rostral end held in place against an anesthesia delivery tube. The hind legs were moderately extended and held in place with clear tape to ensure that a correct anatomical position was achieved (i.e., straight spine) and that the mouse position did not change once the scan procedure was initiated. An initial radiographic image was acquired at 90 degrees to the plane of the mouse bed to allow correct positioning of the mouse by centering the scan acquisition area at the level of the iliac crest of each mouse.

Image reconstruction and analysis. Image reconstruction, whereby a micro-CT scan of an individual mouse was manipulated to produce two-dimensional cross-sectional images, was performed using reconstruction/ visualization software of the MicroCAT instrument (ImTek Inc.). Two sets of reconstructed images per scan were generated for each mouse for the determination of individual fat depot mass. User-defined placement of reconstruction slices was relative to defined anatomical sites (i.e., vertebral segments) (33). The first set of reconstructed images, consisting of six slices (intervertebral segments lumbar 6 and 7 through sacral 4 to caudal 1), provided a montage for the analysis of inguinal and epididymal adipose tissue depots. The second reconstruction set, consisting of nine slices (intervertebral and midvertebral landmarks from lumbar 2 and 3 through lumbar 6 and 7) was used to define retroperitoneal and mesenteric adipose tissue depot masses. Reconstructed bitmap images were converted to tagged image file format images and subsequently analyzed for fat depot mass using Scion Image for Windows (Scion Corp., Frederick, Maryland, USA).

Liver glucose 6-phosphatase and phosphoenolpyruvate carboxykinase gene expression. Total RNA was purified from liver using the RNeasy Mini Kit (QIAGEN Inc., Valencia, California, USA) and treated with DNase according to the manufacturer's instructions. The cDNA was 
prepared from total RNA using Superscript II reverse transcriptase (Invitrogen Corp., Carlsbad, California, USA). Control reactions were run in the absence of reverse transcriptase (minus RT). Expression of liver glucose 6-phosphatase (G6Pase) and phosphoenolpyruvate carboxykinase (PEPCK) genes was quantitated by real-time quantitative PCR (TaqMan; Applied Biosystems Inc., Foster City, California, USA) and normalized to $18 \mathrm{~S}$ rRNA. Minus RT reactions were also amplified in order to confirm that product was not contributed by contaminating genomic DNA. TaqMan PCR was performed by adding $25 \mu \mathrm{l} 2 \times$ PCR Master Mix (Applied Biosystems Inc.), $5 \mu \mathrm{l}$ of $2.5 \mu \mathrm{M}$ probe (see below), $0.5 \mu \mathrm{l}$ each of $30 \mu \mathrm{M}$ forward and reverse primers (see below), and $14 \mu \mathrm{l}$ water to each well of a 96-well plate containing $1 \mathrm{ng}$ of cDNA in a 5- $\mu$ l volume (final volume $50 \mu \mathrm{l})$. Amplification was performed on a 7700 Sequence Detection System (Applied Biosystems Inc.) according to a preset protocol: $50^{\circ} \mathrm{C}$ for 2 minutes, $95^{\circ} \mathrm{C}$ for 10 minutes, followed by 40 cycles of $95^{\circ} \mathrm{C}$ for 15 seconds and $60^{\circ} \mathrm{C}$ for 1 minute. Data were analyzed using the $2^{-\Delta \Delta \mathrm{Ct}}$ method (34) that had been previously validated to demonstrate equivalent amplification efficiencies of the target genes G6P and PEPCK and the reference gene 18S rRNA (data not shown). Probes were custom made by Applied Biosystems Inc.: G6P, 6FAM-AGTCCCTCTGGCCATGCCATGG-TAMRA; PEPCK, 6FAM-AGGGCAAGATCATCATGCACGACCCTAMRA. The primers were made by Invitrogen Corp.: G6P forward, CACCTGTGAGACCGGACCA; G6P reverse, GACCATAACATAGTATACAC-CTGCTGC; PEPCK forward, GACCATAACATAGTATACACCTGCTGC; PEPCK reverse, AGAAGGGTCGCATGGCAA. An 18S rRNA probe and primer kit was obtained from Applied Biosystems Inc.

Liver glycogen synthase activity. Liver samples were homogenized in 10 vol glycogen synthase (GS) homogenization buffer (HB; $10 \mathrm{mM}$ TRIS- $\mathrm{HCl}, \mathrm{pH}$ 7.4, $150 \mathrm{mM} \mathrm{KF}, 15 \mathrm{mM}$ EDTA, $0.6 \mathrm{M}$ sucrose, $1 \mathrm{mM}$ PMSF, $1 \mathrm{mM}$ benzamidine, $25 \mu \mathrm{g} / \mathrm{ml}$ leupeptin, and $50 \mathrm{mM} \beta$-mercaptoethanol) for 30 seconds on ice. Protein concentration of homogenates was determined using Bradford Reagent (Bio-Rad, Hercules, California, USA) and IgG as standards. GS activity was measured according to the low/high G6P method (35). A total reaction volume of $90 \mu \mathrm{l}$ contains $100 \mu \mathrm{M}$ UDP$\left[\mathrm{U}-{ }^{14} \mathrm{C}\right]$-glucose $(\sim 4.5 \mu \mathrm{Ci} / \mu \mathrm{mol}), 50 \mathrm{mM}$ Tris- $\mathrm{HCl}, \mathrm{pH}$ 7.8, $25 \mathrm{mM} \mathrm{KF}, 12.5 \mathrm{mM}$ EDTA, $7 \mathrm{mg} / \mathrm{ml}$ rabbit liver glycogen. In addition, G6P is used at $10 \mathrm{mM}$ to measure total synthase activity $\left(\mathrm{GS}_{\mathrm{d}}+\mathrm{GS}_{\mathrm{i}}\right.$, where $\mathrm{GS}_{\mathrm{d}}$ is the G6P-dependent and $\mathrm{GS}_{\mathrm{i}}$ is the G6P-independent synthase activity) and at $0.1 \mathrm{mM}$ to measure the $\mathrm{GS}_{\mathrm{i}}$ activity. One hundred fifty micrograms of liver homogenate protein is included in a 10 -minute incubation at $30^{\circ} \mathrm{C}$. Reactions are stopped by spotting $65 \mu \mathrm{l}$ onto $1.5 \mathrm{~cm}^{2}$ pieces of Whatman 31 ETCHR (Whatman International Ltd., Maidstone, United Kingdom) chromatography paper, which is dropped into $300 \mathrm{ml}$ ice-cold 50\% ethanol and washed for 5 minutes on a rotator. A second wash is done for 1 hour in $700 \mathrm{ml}$ ice-cold $50 \%$ ethanol followed by 1 minute in $100 \mathrm{ml}$ acetone. The squares are dried for 10 minutes in a $60^{\circ} \mathrm{C}$ oven, placed in scintillation fluid (Ready Safe; Beckman Coulter Inc., Fullerton, California, USA), and counted for ${ }^{14} \mathrm{C}$-glucose incorporation into glycogen on a liquid scintillation counter (LKB Wallac 1219; PerkinElmer Wallac, Gaithersburg, Maryland, USA). The $\mathrm{GS}_{\mathrm{i}}$ disintegrations per minute are divided by the $\left(\mathrm{GS}_{\mathrm{d}}+\mathrm{GS}_{\mathrm{i}}\right)$ activity and expressed as the GS activity ratio.

Isolated muscle glucose-uptake assay. Soleus muscles were isolated from fed, male Akt2-null or control mice, and glucose uptake in the absence or presence of insulin at the indicated concentrations were determined as described previously (36).

\section{Results}

Targeted disruption of the Akt2 gene. Disruption of the Akt 2 gene was accomplished by homologous recombination and consisted of the replacement of $260 \mathrm{bp}$ of the catalytic domain (corresponding to bp 788-1047 of the murine cDNA; U22445) with the neomycin gene (Figure 1a). Southern blot analysis of genomic DNA isolated from DBA/1lacj ES cells confirmed the correct recombination (Figure $1 \mathrm{~b}$ ), and PCR genotyping analysis of $\mathrm{F}_{2}$-generation mice confirmed the generation of Akt2-null mice (Figure 1c). Western blot analysis of protein lysates derived from brains isolated from $A k t 2^{+/+}$and $A k t 2^{-/-}$mice shows no detectable level of Akt2 protein in $A k t 2^{-/-}$mice (Figure $1 \mathrm{~d}$ ). Thus, the targeted disruption resulted in a functionally null allele. Phenotype of Akt2 KO mice. The Akt2 $2^{--}$mice (genetic background: DBA/1lacJ) are viable, and examination of 49 pups (ten litters) from matings between two Akt 2 heterozygous mice showed a Mendelian ratio among $\mathrm{Akt2}^{+/+}$ (wild-type), $A k t 2^{+/-}$(heterozygous), and $A k t 2^{-/-}$(homozygous) mice. In contrast to a previous report, both male and female Akt2-null mice exhibited a mild growth deficiency. At birth, Akt2-null mice were $8 \%$ smaller than control mice $(1.37 \pm 0.03$ g versus $1.48 \pm 0.03 \mathrm{~g}$, respectively; $P<0.05)$. This decrease in body weight persisted throughout life, averaging $13 \%$ and $16 \%$ for male and female Akt2-null mice, respectively, over 6 months $(P<0.01$ for both from 5 to 24 weeks of age; $n=9-13$ per group). Akt2-null mice also exhibit a modest but significant $(P<0.01)$ decrease in length as compared with control mice, with a difference averaging $5 \%$ evident from 6 to 11 weeks of age.

Comparison of body and selected organ weights of 7-week-old Akt2-null and wild-type mice revealed several interesting differences (Table 1). While body weight was reduced by $16 \%$ in both males and females, the relative weight of brain and liver were increased by approximately $10 \%$ in Akt2-deficient mice of both sexes (Table 1). In contrast, the relative amount of brown adipose tissue was reduced significantly in both males (13\%) and females (20\%), whereas white adipose tissue, as assessed by weight of the gonadal fat pad, was reduced by more than $50 \%$ in females, but not significantly in males (Table 1). 
a

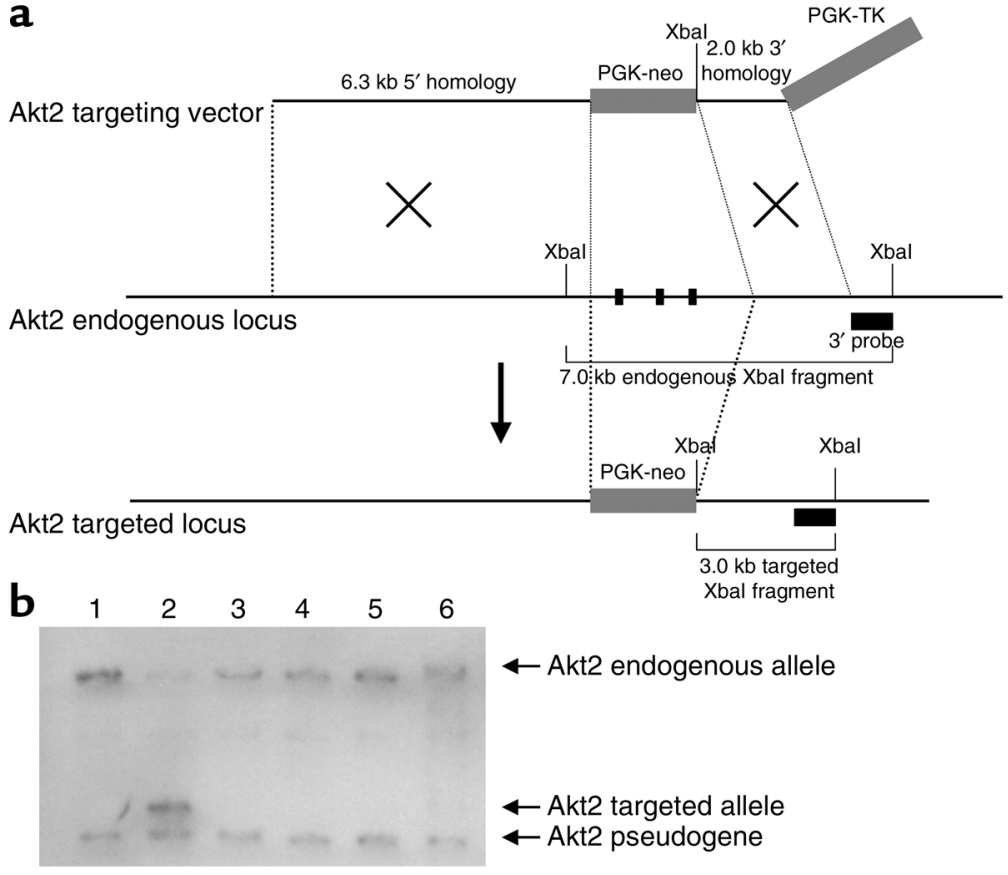

C

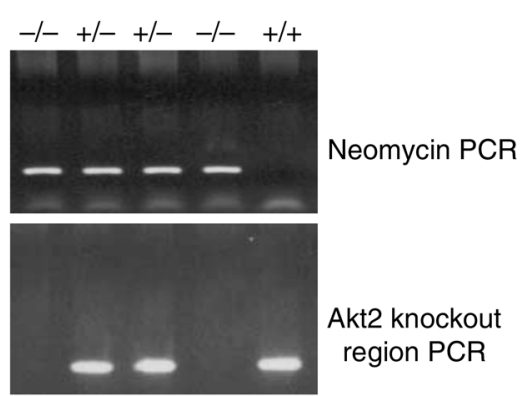

d

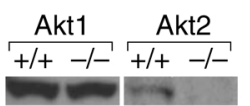

\section{Figure 1}

Generation of Akt2-deficient mice. (a) Illustration depicting strategy for homologous recombination in DBA/1/ac) ES cells. The locations of the $3^{\prime}$ probe and Xbal recognition sites used for Southern blot screening of the ES cells are indicated. The PGK-neo cassette was inserted in the same orientation as the Akt2 gene. (b) Southern blot analysis of DNA isolated from ES cells transfected with the Akt2 targeting vector. Genomic DNA from six ES cell clones was isolated and digested with Xbal restriction endonuclease and hybridized with the external 1.0-kb BamHI/Xbal 3' probe. This probe will recognize a 7.0-kb endogenous, $3.0-\mathrm{kb}$ targeted, and 2.7-kb Akt2 pseudogene Xbal fragment. The probe recognizes the pseudogene due to the presence of a $3^{\prime}$ exon, also contained in the Akt2 pseudogene sequence. Note that only clone 2 contains the targeted allele. (c) $\mathrm{PCR}$ genotyping analysis of $\mathrm{F}_{2}$-generation mice. Two PCR reactions are performed on each sample; one is specific for a targeted allele (top panel) and the other is specific for the Akt2 locus within the knockout region (bottom panel). Taken together, all three genotypes, wild-type, heterozygous, and homozygous (+/+, +/-, and -/-), can be determined. (d) Western blot analysis of protein extracts from brains isolated from $A k t 2^{+/+}$and $A k t 2^{-/-}$mice. The blot to the left was hybridized with an anti-Akt1 Ab and the one to the right with an anti-Akt2 Ab.

To further explore the observed differences in fatpad weights, micro-CT scanning was used to assess the size of multiple adipose depots. Akt2-null animals (22 weeks of age) were found to exhibit significant lipoatrophy, with all adipose depots in both males and females being dramatically reduced in size (Figure 2 and Figure 3). The reduction in size of the fat depots in females was $80-90 \%$ (Figure 2, c and d, and Figure $3 a)$. In 22 -week-old males, which had normal fat pad mass at 7 weeks (Table 1), a reduction of $65-75 \%$ in the inguinal-subcutaneous and epididymal depots was observed, and the retroperitoneal and mesenteric depots were almost completely absent (Figure 2, a and $\mathrm{b}$, and Figure $3 \mathrm{~b}$ ). The more significant reduction in size of the gonadal fat pads in both males and females at 22 weeks (Figure 3) relative to 7 weeks (Table 1) suggests that loss of adipose tissue is progressive with age. Consistent with this, the weight of the epididymal fat pad was found to be similar in male control and Akt 2 -null mice at 9 weeks of age $(0.21 \pm 0.04$ versus $0.18 \pm 0.02 \mathrm{~g}$, control and Akt2-null mice, respectively; $P>0.05$ ) but was reduced $24 \%$ in Akt2-null mice at 12 weeks of age $(0.21 \pm 0.11$ versus $0.158 \pm 0.017$, control and Akt2-null mice, respectively; $P<0.05$ ). Morphometric analysis of adipose tissue from Akt2-null and control mice indicated that adipocyte size was not significantly different at either 9 or 12 weeks ( 9 week: $9.8 \pm 1.9$ versus $11.0 \pm 3.9$ adipocytes per unit area; 12 week: $9.0 \pm 1.7$ versus $11.1 \pm 3.4$ adipocytes per unit area, control versus Akt2-null, respectively). This indicates that the decrease in adipose mass is due to a decrease in cell number. As observed in other lipoatrophic syndromes, plasma triglycerides were elevated $60 \%$ in male Akt2-null mice $(248 \pm 21 \mathrm{mg} / \mathrm{dl}$ versus $154 \pm 24 \mathrm{mg} / \mathrm{dl}$, Akt2-null and control, respectively; $P<0.05)$. The decrease in adipose tissue was also reflected in a decrease of $30 \%$ in plasma leptin concentration in male Akt 2 -null mice $(2.5 \pm 0.1$ versus $3.5 \pm 0.5 \mathrm{ng} / \mathrm{ml}$ for Akt2-null and wild-type, respectively; $P<0.05)$ and a trend toward lower leptin concentration in females $(2.3 \pm 0.1$ versus $3.1 \pm 0.4 \mathrm{ng} / \mathrm{ml}$, Akt2-null and wild-type, respectively; $P=0.09$ ).

Both male and female Akt2-null mice exhibited fasting hyperglycemia and glucose intolerance (Figure 4). Fed hyperglycemia was observed in 5-week-old male Akt2-null mice $(220 \mathrm{mg} / \mathrm{dl}$ versus $170 \mathrm{mg} / \mathrm{dl}$ for Akt2 null and wild-type, respectively; $P<0.001$ ) and became more severe with age (Figure 5a). Female mice exhibited a milder fed hyperglycemia that did not become significantly elevated until 10 weeks of age (Figure 5a; 
Table 1

Body and organ weights in $A k t 2^{-/-}$and $A k t 2^{+/+}$mice

Fold change of $A k t 2^{-/-}$versus $A k t 2^{+/+}$

Males

Females

\begin{tabular}{lcccc} 
& Absolute & $\begin{array}{c}\text { Relative to } \\
\text { body weight }\end{array}$ & Absolute & $\begin{array}{c}\text { Relative to } \\
\text { body weight }\end{array}$ \\
Body weight & $0.84^{\mathrm{B}}$ & $\mathrm{NA}$ & $0.84^{\mathrm{B}}$ & $\mathrm{NA}$ \\
$\begin{array}{l}\text { Brain } \\
\text { Brown }\end{array}$ & $0.92^{\mathrm{B}}$ & $1.09^{\mathrm{A}}$ & $0.94^{\mathrm{A}}$ & $1.11^{\mathrm{A}}$ \\
$\begin{array}{l}\text { (interscapular) } \\
\text { adipose tissue }\end{array}$ & $0.73^{\mathrm{B}}$ & $0.87^{\mathrm{A}}$ & $0.67^{\mathrm{B}}$ & $0.80^{\mathrm{A}}$ \\
Kidney & $0.70^{\mathrm{B}}$ & $0.80^{\mathrm{B}}$ & $0.81^{\mathrm{B}}$ & 0.96 \\
Liver & 0.95 & $1.12^{\mathrm{A}}$ & 0.93 & $1.09^{\mathrm{A}}$ \\
$\begin{array}{l}\text { White } \\
\text { (reproductive) }\end{array}$ & & & & \\
adipose tissue & 0.79 & 0.93 & $0.40^{\mathrm{B}}$ & $0.47^{\mathrm{B}}$ \\
Spleen & $0.71^{\mathrm{B}}$ & $0.85^{\mathrm{A}}$ & 0.87 & 1.03 \\
Thymus & $0.76^{\mathrm{B}}$ & 0.91 & 0.94 & 0.91 \\
\hline
\end{tabular}

Terminal body and selected organ weights were determined for $A k t 2^{+/+}$and $A k t 2^{-/-}$male and female mice. A Student $t$ test was used to compare terminal body and organ weights between wild-type and knockout mice. ${ }^{A} P \leq 0.05$; ${ }^{\mathrm{B}} \mathrm{P} \leq 0.01 ; n=10$ each of $A k t 2^{-/-}$and $A k t 2^{+/+}$mice.

$185 \mathrm{mg} / \mathrm{dl}$ versus $160 \mathrm{mg} / \mathrm{dl}$ for wild-type, $P=0.001)$ and remained stable until 1 year of age $(182 \mathrm{mg} / \mathrm{dl}$ versus $160 \mathrm{mg} / \mathrm{dl} ; P=0.024)$. Plasma insulin levels, however, were elevated in both males and females at all ages (Figure 5b). In 5-week-old male and female Akt2null mice, plasma insulin was elevated 2.6- and 3.6fold, respectively (males, 4.5 versus $1.7 \mathrm{ng} / \mathrm{ml}$, and females, 5.8 versus $1.6 \mathrm{ng} / \mathrm{ml}$, Akt 2 -null and control, respectively). While insulin levels in female Akt2-null mice remained stable for the duration of the 6-monthlong study (Figure 5b), average insulin levels in male Akt2-null mice increased further with age, suggestive of deteriorating insulin sensitivity. Furthermore, insulin levels in Akt2-null males were more heterogeneous than in females, due in part to mice exhibiting two distinct patterns of insulinemia and glycemia over the 6-month-period of observation. Three mice (25\%) from this group exhibited a transient hyperinsulinemia that peaked at 8 weeks of age, followed by a decline in plasma insulin to undetectable levels by $15-18$ weeks of age, suggestive of $\beta$ cell failure (Figure 6a). This was accompanied by progression to extreme hyperglycemia (Figure 6a), with blood glucose values greater than $500 \mathrm{mg} / \mathrm{dl}$ evident by 12 weeks of age. The remaining mice exhibited a more stable and milder, albeit significant, hyperglycemia in the face of steadily increasing plasma insulin levels (Figure 6b), consistent with deteriorating insulin sensitivity. Notably, in three separate cohorts of male

Figure 2
Akt2-null mice, a high percentage exhibited hypoinsulinemia with accompanying extreme hyperglycemia: $100 \%(n=6)$ of 8 -month-old mice (Figure 7$)$, $80 \%(n=5)$ of 20 -week-old mice, and $92 \%(n=25)$ of 7- to 8-month-old mice (data not shown). Thus, 75\% of 48 male Akt2-null mice progressed to this extreme diabetic phenotype between 5 and 8 months of age. The two groups of mice depicted in Figure 6 may reflect temporal differences in the progression of the phenotype in the population or, conversely, different susceptibilities to development of more extreme diabetes, possibly due to differences in prenatal or perinatal nutrition $(37,38)$.

To determine whether impaired glucose disposal into skeletal muscle contributed to the hyperglycemia and insulin resistance of $\mathrm{Akt} 2$-null mice, glucose uptake into isolated soleus muscles was examined (Figure 8). No difference was observed in basal glucose uptake into muscles from control and Akt2-null mice. Submaximal ( $1 \mathrm{nM})$ insulin, however, failed to increase glucose uptake above basal level, and uptake in response to maximal $(100 \mathrm{nM})$ insulin was reduced in muscles from Akt2-null mice (Figure 8). Thus, the lack of Akt2 in skeletal muscle decreased both the insulin sensitivity and responsiveness of glucose transport.

Regulation of enzymes involved in glucose production and storage in liver was also abnormal in Akt2-null mice. Expression of PEPCK, the rate-limiting enzyme of gluconeogenesis, was elevated prior to $\beta$ cell failure in livers of diabetic, 7-week-old, fed Akt2-null mice 1.9fold relative to control $(P<0.05$; Table 2$)$. At 24 weeks of age, the level of PEPCK expression was consistent with the prevailing glycemia, being elevated 4.1-fold $(P<0.01)$ in the subset of hypoinsulinemic, hyperglycemic (Figure 6a) Akt2-null mice, although it was not different between control and hyperinsulinemic
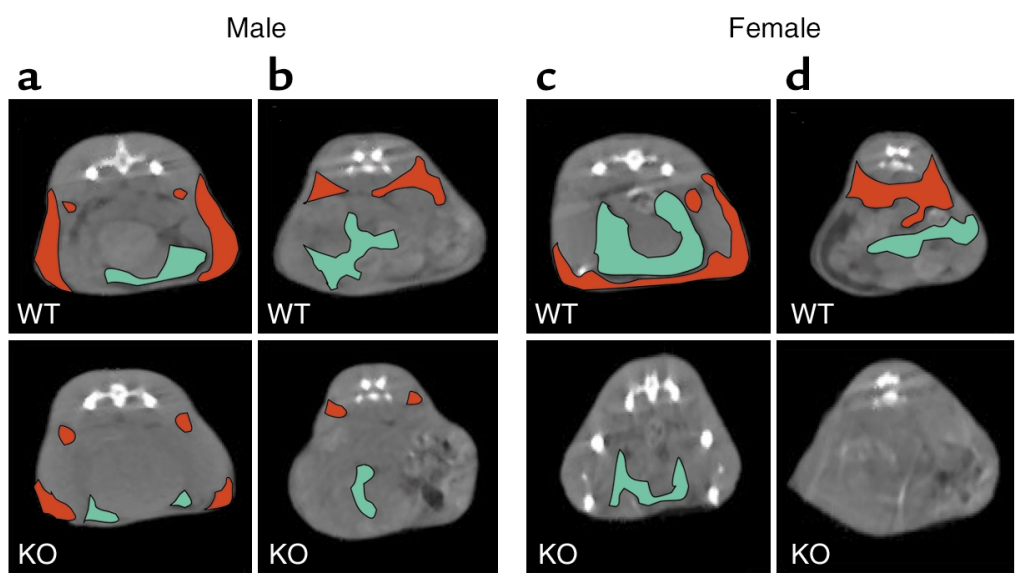

Adipose tissue mass is decreased in Akt2-null mice. Representative cross-sectional images of wild-type (WT) and Akt2-null (KO) male ( $\mathbf{a}$ and $\mathbf{b}$ ) and female ( $\mathbf{c}$ and $\mathbf{d}$ ) mice subjected to micro-CT analysis of in situ adipose tissue mass. ( $(a$ and $\mathbf{c}$ ) The inguinal subcutaneous (red) and epididymal/gonadal (green) depots and (b and $\mathbf{d}$ ) the retroperitoneal (red) and mesenteric (green) depots are demarcated for illustration of the gross effect of the Akt2 deficiency on adipose tissue mass. 

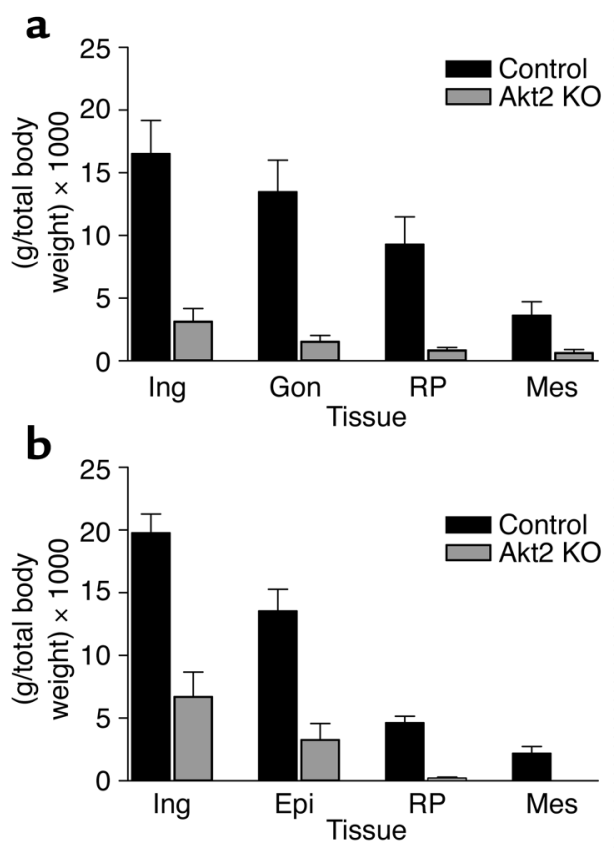

(Figure 6b) Akt2-null mice that exhibited only mild hyperglycemia (Table 2). The G6Pase gene expression was not elevated in Akt2-null mice either at 7 or 24 weeks of age, except in the subset of hypoinsulinemic Akt2-null mice, in which the level of G6Pase mRNA was elevated 2.2 -fold $(P<0.05$; Table 2$)$. The proportion of liver GS in the active state did not differ between fed control and Akt2-null mice at 21 weeks of age (activity ratio, $0.055 \pm 0.009$ versus $0.070 \pm 0.011$, control and Akt2 null, respectively, $P=0.312$ ). Total GS activity measured in the presence of high $(10 \mathrm{mM})$ glucose-6-phosphate was reduced $46 \%$ in severely diabetic Akt 2 -null mice $(P<0.05)$, however, suggesting that the absolute amount of active GS was decreased. Nine-week-old Akt2null mice that were still hyperinsulinemic, did not exhibit this decrease in total liver GS activity.

Pancreas morphometry and insulin immunohistochemistry. At 7 and 24 weeks of age, no significant difference in either the number or size of pancreatic islets was observed in either male or female hyperinsulinemic Akt2-null mice relative to control mice (data not shown). Pancreata from the hypoinsulinemic/hyperglycemic male Akt2-null mice (Figure 6a and Figure 7), however, were characterized by a variable $(10-59 \%)$ decrease in the total number of islets as compared with their wild-type controls (data not shown). The vast majority of the remaining islets in this cohort of mice were distorted and contained only a few $\beta$ cells scattered within the exocrine pancreas (Figure 9c). The percentage of islets containing apoptotic cells, as indicated by caspase- 3 staining, was increased in pancreata from 24-week-old, hypoinsulinemic, male Akt2-null mice (37\% of the remaining islets or islet remnants from hypoinsulinemic Akt2-null mice contained one or more apoptotic cells versus less than $2 \%$ of islets from control or hyperinsulinemic Akt2-null mice).

\section{Figure 3}

Adipose tissue mass is decreased in Akt2-null mice. Adipose tissue mass of wild-type and Akt2-null mice was determined by micro-CT scanning in four regional depots, the inguinal subcutaneous (Ing), epididymal/gonadal (Epi/Gon), retroperitoneal (RP), and mesenteric (Mes) regions. Adipose tissue mass was significantly $(P<0.05)$ reduced in both female (a) and male (b) Akt2-null mice. In female Akt2-null mice adipose depot mass was reduced $80-90 \%$ in all depots measured. In male Akt2-null mice adipose depot mass was reduced $65-75 \%$ in the inguinal and epididymal depots, and more than $95 \%$ in the retroperitoneal and mesenteric depots.

Occasionally, inflammatory and necrotic cells or mitotic figures were observed within those remaining islets. Islets from wild-type mice had abundant intracytoplasmic insulin staining in $\beta$ cells (Figure 9a). Insulin staining was diffuse and uniform, except for cells at the periphery of the islets, which stained positive for glucagon (data not shown). A decrease, predominantly in males, in the intensity of staining for insulin in the cytoplasm of $\beta$ cells was observed in islets from Akt2-null mice (Figure $9 \mathrm{~b}$ ). The remaining $\beta$ cells contained variable amounts of intracytoplasmic insulin interspersed with areas lacking immunohistochemical staining. The decreased staining for insulin in the $A k t 2^{-/-}$mice was already evident at 7 weeks but did not progress in incidence or severity by 24 weeks of age. The islets from the hypoinsulinemic/hyperglycemic males (Figure 6a and Figure 7) were characterized by loss of normal islet architecture and severe loss of insulin staining with only occasional, weak, intracytoplasmic staining of a few remaining cells, consistent with the very low levels of plasma insulin in these animals (Figure 9c).

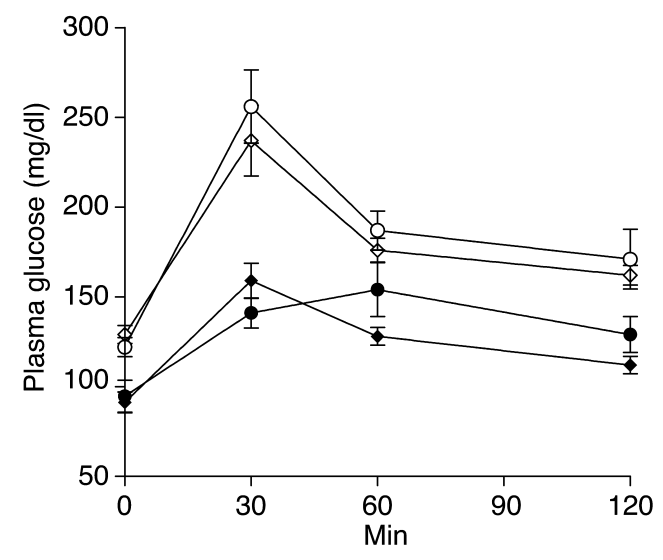

Figure 4

Seven-week-old Akt2-null mice exhibit fasting hyperglycemia and glucose intolerance in an oral glucose-tolerance test. Blood samples were taken from overnight-fasted Akt2-null (open symbols) and wild-type (filled symbols) mice at time zero. Mice were immediately given an oral dose of glucose $(1 \mathrm{~g} / \mathrm{kg})$, and blood was sampled at the indicated times. Plasma glucose levels were significantly elevated in both male and female Akt2-null mice (open circles and diamonds, respectively) relative to wild-type male and female mice (filled circles and diamonds, respectively) at time zero and 30 minutes following the glucose load. 

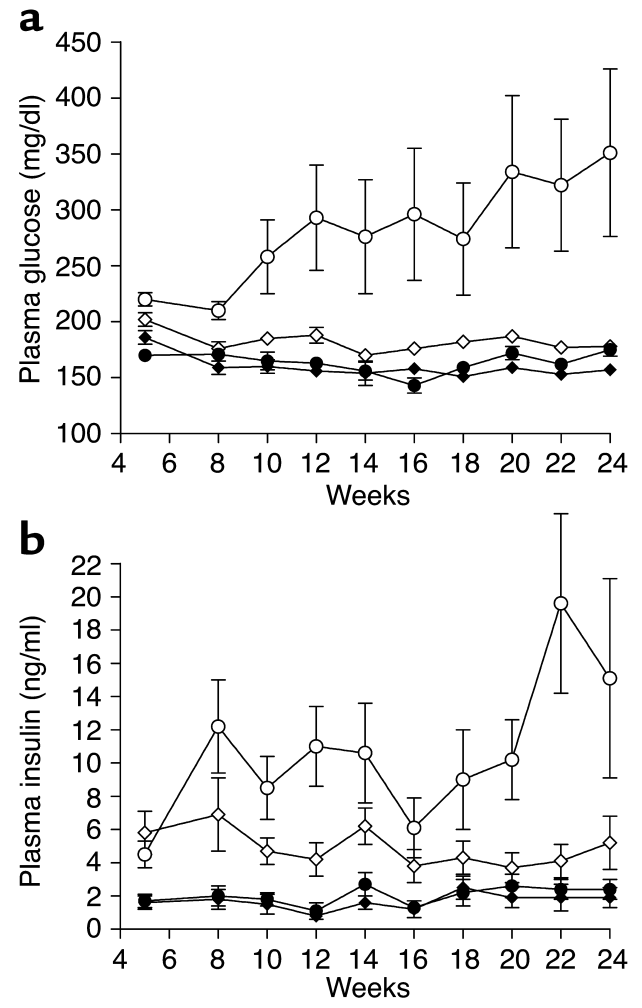

\section{Discussion}

The data reported here demonstrate that Akt2 regulates both growth and glucose metabolism. Akt2-null mice exhibited mild growth deficiency, age-dependent loss of adipose tissue, glucose intolerance, insulin resistance as evidenced by elevated plasma insulin levels, dyslipidemia, and hyperglycemia, which progressively worsened in a substantial portion of males to a severe form of diabetes that was accompanied by $\beta$ cell failure and loss. This complex phenotype implicates $\mathrm{Akt} 2$ as a key intermediate in signaling from both insulin and IGF-1 receptors and, furthermore, suggests specific roles for Akt 2 in maintenance of adipose tissue and $\beta$ cell mass.

Similar to Akt1-null mice $(23,24)$, Akt2-null mice were born smaller and exhibited a $13-15 \%$ decrease in body weight relative to their wild-type counterparts at all ages. The body length of Akt2-null mice was also modestly but significantly decreased. Collectively, these findings suggest that the loss of Akt 2 confers a growth deficiency that is due in part to a decrease in body size as well as a decrease in body weight. The moderate growth deficiency in Akt2-null mice described here is similar in magnitude to that observed in insulin

\section{Figure 6}

Diabetic phenotype of male Akt2-null mice. (a) Plasma glucose (filled symbols) and insulin (open symbols) levels in three male Akt2-null mice from Figure 5 exhibiting $\beta$ cell failure (see Figure 9). (b) The remaining nine male Akt2-null mice were mildly hyperglycemic (filled diamonds) while becoming increasingly hyperinsulinemic (open squares), or insulin resistant, with age.

\section{Figure 5}

Hyperglycemia and hyperinsulinemia in male and female Akt2-null mice. Plasma glucose (a) and insulin (b) levels were determined every 14 days in male wild-type (filled circles, $n=11$ ), male Akt2-null (open circles, $n=12$ ), female wild-type (filled diamonds, $n=9$ ), and female Akt2-null (open diamonds, $n=13$ ) mice.

receptor or IRS-2-deficient mice (10\%; refs. 39, 40). Interestingly, Akt2-deficient mice described in a recent report (25) were diabetic but did not exhibit a growth deficiency. The likely explanation for the difference between the growth phenotype of those mice and the Akt2-null mice described here may lie in the genetic background of the different knockout lines. In fact, genetic background has been observed to have significant modifying effects on the phenotypes of a number of targeted deletions of genes in the insulin pathway (41-43). The previously described Akt2-null mice (25) were on a mixed 129/C57BL/6 genetic background, whereas the mice described here are on an inbred DBA/1lacJ background. Consistent with the previous report, the growth deficiency due to lack of $\mathrm{Akt} 2$ is not observed on a hybrid DBA/1lacJ/C57BL/6 background (44). This suggests that the decreased size of Akt2-null mice described here is not due to metabolic abnormalities per se, but that the role of Akt2 in growth regulation is more obvious in the presence of modifying genes contributed by the DBA/1LacJ background. A role for Akt 2 in growth regulation is further supported by the phenotype of Akt1/Akt2 doubleknockout mice, which are much smaller than mice deficient in only Akt1 or Akt2 (44). The apparent increase in size of brain and liver in the generally smaller
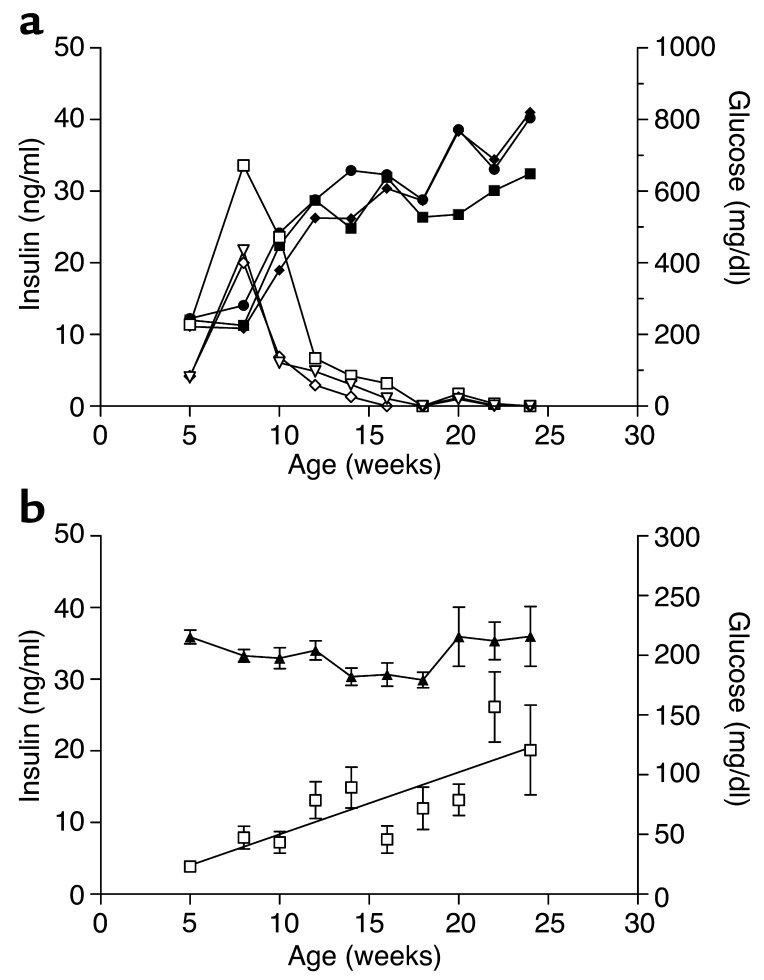

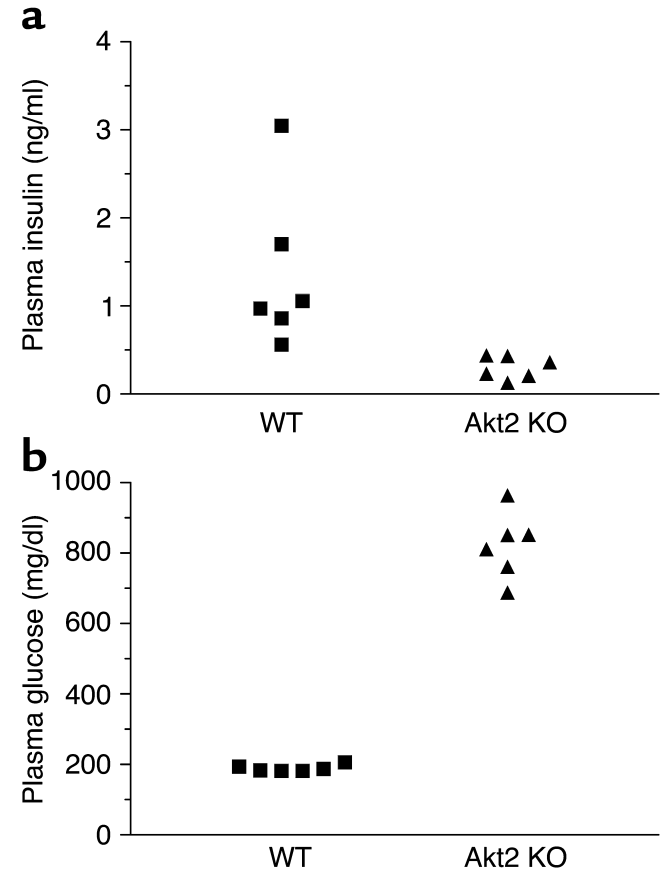

Figure 7

Male Akt2-null mice become severely hypoinsulinemic and hyperglycemic by 8 months of age. A group $(n=6)$ of 8 -month-old male Akt2-null (KO) mice were hypoinsulinemic (a) and extremely hyperglycemic (b) relative to age-matched wild-type males.

Akt2-null mice (Table 1) suggests that other Akt isoforms can compensate or might play more significant roles in growth regulation of these tissues.

Akt2-null mice exhibited progressive lipoatrophy with a decrease in adipose tissue mass observed in all depots (Figures 2 and 3). Morphometric analysis of epididymal fat pads revealed that the decrease in adipose tissue mass was not due to a decrease in adipocyte size, indicating that it was due to decreased adipocyte number. The loss of adipose tissue cannot completely account for the observed decrease in body weight in Akt2-null mice, since 7-week-old male Akt2-null mice weighed $16 \%$ less than wild-type mice despite adipose tissue mass that was proportionally normal (Table 1). The lipoatrophy is unlikely to be due to wasting associated with a type 1 diabetes-like insulinopenia because it was evident in male Akt2-null mice prior to $\beta$ cell failure as well as in females with elevated but stable glycemia and insulinemia. The food intake of Akt2-null mice was also not significantly different from control mice (data not shown). These data suggest that the loss of adipose tissue is directly related to the lack of Akt2 activity. The fact that Akt has been implicated in control of both adipocyte differentiation and apoptosis, either of which could contribute to the progressive decrease in adipocyte number, lends support to this hypothesis. Constitutively active Akt will induce spontaneous adipocyte differentiation (45), and inhibition of Akt activity induces apoptosis of adipocytes (46). Recent data indicate that the differentiation of murine embryonic fibroblasts from Akt2-null mice into adipocytes in vitro is not significantly impaired (44), suggesting that the lipopatrophy observed in Akt2-null mice is due to either increased adipocyte apoptosis or decreased proliferation of adipocyte precursors. Notably, the abundance of Akt2 as well as its insulinstimulated activity is twofold higher than that of Akt1 in differentiated adipocytes, and Akt 3 activation is barely detectable (14). These data, along with the observation reported here that loss of Akt2 leads to lipoatrophy, suggest that Akt2 is the primary Akt isoform involved in adipocyte insulin signaling and in the regulation of adipose mass.

Furthermore, among mouse models made insulin resistant by disruption of insulin-signaling pathway genes, only Akt2-null mice, insulin receptor-null mice (39), and mice with loss of insulin receptors specifically in fat (FIRKO mice) exhibit decreased adipose tissue. FIRKO mice maintain normal glucose homeostasis because insulin sensitivity is maintained in other tissues (47). Mice with tissue-specific deletion of the insulin receptor in muscle (MIRKO), brain, $\beta$ cells, or liver (LIRKO), expression of dominant negative insulin receptor in muscle, IRS-2-null mice, or mice with impaired insulin clearance due to expression of a dominant negative CEACAM1 in liver all exhibit increased adipose mass $(43,48)$, however. Except for MIRKO mice, all are also hyperinsulinemic. Thus, the progressive lipoatrophy in Akt2-null mice despite hyperglycemia and hyperinsulinemia is a distinct feature of the Akt2-null phenotype and further supports the hypothesis that Akt2 plays a critical role in the regulation of adipocyte mass.

The Akt2-null mice described here exhibited impaired insulin-stimulated glucose uptake into skeletal muscle, similar to that described previously (25), and elevated hepatic PEPCK gene expression, both of which would contribute to the observed hyperglycemia. The elevated level of PEPCK gene expression in 7-week-old male, Akt2-null mice, despite plasma

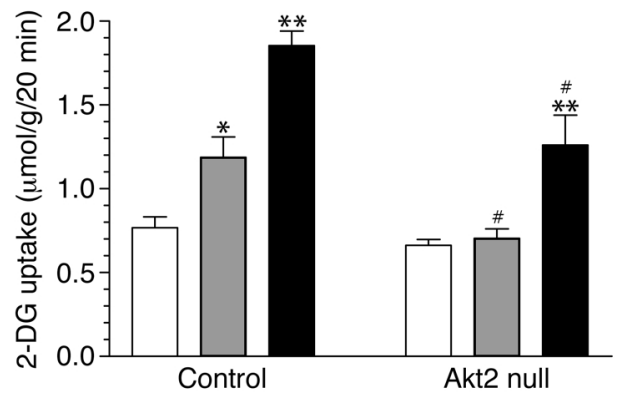

\section{Figure 8}

Muscle glucose uptake is impaired in Akt2-null mice. The 2-deoxyglucose (2-DG) uptake into isolated soleus muscles from male control and Akt2-null mice was determined in the absence of insulin (basal, white bars) or in the presence of a submaximal ( $1 \mathrm{nM}$, gray bars) or maximal ( $100 \mathrm{nM}$, black bars) concentration of insulin. ${ }^{*} P<0.05$ versus corresponding basal; ${ }^{*} P<0.01$ versus corresponding basal; ${ }^{\#} P<0.05$ versus corresponding insulin-treated control sample. 
Table 2

Expression of gluconeogenic enzymes in liver of male control and Akt2-null mice

\begin{tabular}{|c|c|c|c|c|c|}
\hline \multirow[t]{2}{*}{ Age } & \multicolumn{2}{|c|}{7 weeks } & \multicolumn{3}{|c|}{24 weeks } \\
\hline & Control & Akt2 null & Control & Akt2 null Ins-H & Akt2 null Ins-L \\
\hline Plasma glucose (mg/dl) & $233 \pm 11$ & $376 \pm 19^{A}$ & $175 \pm 6$ & $216 \pm 25$ & $758 \pm 55^{A}$ \\
\hline Plasma insulin (ng/ml) & $0.85 \pm 0.1$ & $5.4 \pm 0.8^{A}$ & $2.4 \pm 0.6$ & $20.1 \pm 6.3^{\mathrm{A}}$ & ND \\
\hline PEPCK mRNA ${ }^{B}$ & 2.8 & $5.3^{\mathrm{A}}$ & 4.4 & 2.3 & $18.4^{\mathrm{A}}$ \\
\hline G6Pase mRNA ${ }^{B}$ & 1.9 & 1.2 & 1.2 & 0.96 & $2.6^{\mathrm{A}}$ \\
\hline
\end{tabular}

Twenty-four-week old Akt2-null mice are separated into hyperinsulinemic and hypoinsulinemic groups. ${ }^{A} P<0.05$ versus control. ${ }^{B}$ The mRNA levels were determined by quantitative RT-PCR as described in Methods and expressed as arbitrary units. ND, not detectable; Ins-H, hyperinsulinemic; Ins-L, hypoinsulinemic.

insulin levels that were sixfold higher than control animals (Table 2), is consistent with a high degree of liver insulin resistance. PEPCK expression, however, was not elevated in Akt2-null mice that sustained sufficient hyperinsulinemia to maintain a near-normal glycemia (Table 2), suggesting that Akt2 is not an absolute requirement for regulation of this gene. Similarly, G6Pase expression was not elevated in Akt2-null mice except in those that exhibited pancreatic $\beta$ cell failure, suggesting that the increase in expression resulted from a more general decrease in insulin signaling, rather than a loss of Akt2 specifically.

The normal response of the endocrine pancreas to peripheral insulin resistance is a compensatory increase in $\beta$ cell mass (49). Mice with heterozygous insulin receptor (IR) deletion $\left(I R^{+/}\right)$, double heterozygous deletion of IR and IRS-1 (IR/IRS-1+/-), IRS-1-/- mice, and LIRKO mice exhibit twofold to tenfold increases in $\beta$ cell mass and hyperinsulinemia (40, 50-52). Female Zucker diabetic fatty (ZDF) rats exhibit islet hypertrophy and hyperinsulinemia sufficient to compensate for their insulin resistance and do not develop diabetes (49). Limited data from humans is consistent with that from animal models and suggest that $\beta$ cell mass is increased in obese, insulin-resistant subjects (49). Thus, a major distinction between the Akt2-null phenotype described here and most insulin-resistant models, including the previously described Akt2-null mice (25), is the failure of pancreatic islet mass to increase in response to peripheral insulin resistance. This may indicate that proliferation or neogenesis of $\beta$ cell precursors is impaired in the Akt2-null mice described here. The observation that the insulin content of $\beta$ cells in hyperinsulinemic male Akt2null mice appeared lower (Figure $9 \mathrm{~b}$ ) suggests that in the absence of islet hypertrophy, $\beta$ cells were compensating for the insulin resistance by secreting more insulin per cell. Similarly, hyperinsulinemia is observed in diabetic

\section{Figure 9}

Insulin immunohistochemical analysis of $\beta$ cells in male Akt2-null mice. Representative pancreatic islets from (a) a 7-week-old wild-type DBA/1lacJ mouse, (b) a 7-week-old Akt2-null mouse, and (c) a 24week-old Akt2-null mouse displaying the hypoinsulinemic/hyperglycemic phenotype (Figure 6a). The remaining $\beta$ cells of the latter mouse were interspersed between the exocrine pancreatic cells and exhibited little to no cytoplasmic staining.
Psammomys obesus despite a decrease in islet insulin content (53). Furthermore, in male Akt2-null mice increased apoptosis was associated with the eventual loss of $\beta$ cells, resulting in hypoinsulinemia and extreme hyperglycemia. Therefore, the $\beta$ cell phenotype of Akt2-null mice described here resembles most closely that of diabetic models, such as male ZDF rats, in which islet mass fails to increase sufficiently, leading to hyperglycemia (54), and IRS-2-null mice, which exhibit significantly reduced $\beta$ cell mass and develop diabetes as a result of
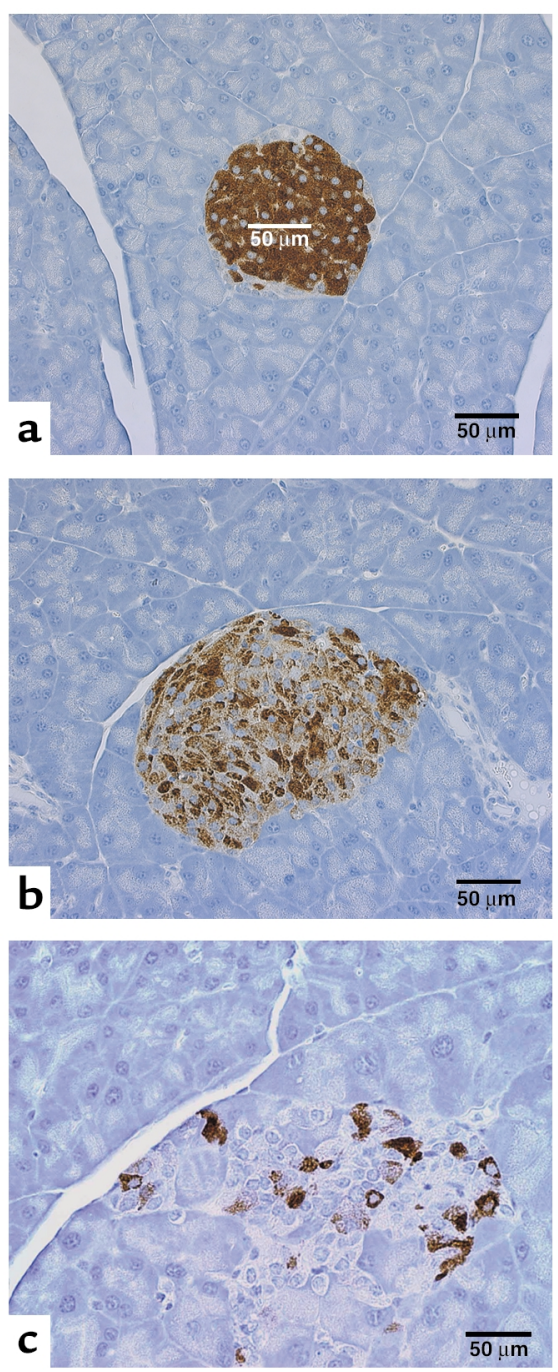
the failure of islet hyperplasia $(40,42,55)$. The $\beta$ cell phenotype of IRS-2-null mice with peripheral insulin resistance is more severe than that observed in Akt2null mice, as indicated by the greater than $90 \%$ decrease in $\beta$ cell area in 4-week-old Irs ${ }^{1 /-}$ Irs $2^{-/-}$mice (55). This suggests that in Akt2-null mice the other Akt isoforms may allow some signaling downstream of IRS- 2 and partially offset the lack of Akt 2 in $\beta$ cells, although Akt 1 and Akt 3 are apparently unable to substitute for Akt2 in mediating the hypertrophy or hyperplasia that is required to compensate for peripheral insulin resistance. In contrast to our observations, $\beta$ cell mass was reported to increase in mice in which the Akt2 deficiency was generated on the $129 / \mathrm{C} 57 \mathrm{BL} / 6$ background (25). The increased $\beta$ cell mass is likely to contribute to the milder phenotype exhibited by those mice. Notably, the diabetic phenotypes of IRS-2-deficient mice $(40,42)$ as well as $o b / o b$ mice (30) also vary in severity depending on the genetic background, with one background exhibiting greater $\beta$ cell loss than the other. Furthermore, the line of IRS-2-null mice with the more severe islet phenotype also exhibits a $10 \%$ growth deficiency (40). It is interesting that two aspects of the Akt2-null phenotype observed in the mice described here but not in those on the hybrid $129 / \mathrm{C} 57 \mathrm{BL} / 6$ background, the growth deficiency and failure of $\beta$ cell mass to increase, are both regulated primarily by IGF-1 receptor signaling $(39,55)$. This leads one to speculate whether a difference in these genetic backgrounds may lie in genes modifying the strength of signaling through the IGF-1 receptor. Curiously, a number of reports have documented an inverse correlation between height and the incidence of type 2 diabetes, insulin resistance, or glucose intolerance in humans (56-59). Since IGF-1 receptor signaling is the primary determinant of somatic growth, these data, taken together, raise the possibility that signaling through the IGF-1 pathway is protective for diabetes and further suggest that the basis of this protective action may lie in the role of IGF-1 signaling in $\beta$ cell preservation or adaptation.

The pattern of transient hyperinsulinemia followed by relative hypoinsulinemia and hyperglycemia in male Akt2-null mice resembles closely that observed in diabetic models such as the ZDF rat (60), IRS-2-null mice (40), the desert gerbil, P. obesus, on a high-energy diet (53), and even human type 2 diabetics (61). Data suggest that increased $\beta$ cell apoptosis contributes to the $\beta$ cell failure observed here and in the other rodent models $(53-55,62)$. The important antiapoptotic role of Akt is well documented (9), and the data reported here suggest that Akt 2 may play a uniquely important role downstream of IRS- 2 in preventing apoptosis of $\beta$ cells in the face of hyperglycemic stress. A recent report suggests that heterozygous deletion of an Akt substrate, the Forkhead transcription factor Foxo1, can rescue the loss of $\beta$ cells in IRS-2-deficient mice (63). Since phosphorylation of Forkhead transcription factors by Akt is part of the mechanism whereby Akt promotes cell survival (64), the Akt2 isoform may provide the link between IRS- 2 and Forkhead transcription factors in mediating survival of $\beta$ cells.

In summary, the phenotype of Akt2-null mice described here provides insight into unique and shared roles of this Akt isoform. Akt2 and Akt1 participate in the regulation of body size, whereas Akt2 appears to play a primary role in glucose homeostasis through regulation of insulin action in peripheral tissues, adipose mass, and $\beta$ cell growth and/or survival in response to peripheral insulin resistance.

\section{Acknowledgments}

We are grateful to Margaret Wilhelms, Catherine Tabor, Kim Kowsz, Anne Brodeur, and William Zavadoski for expert technical assistance and to Janice C. Parker, Walter C. Soeller, and Nissim Hay for critical reading of the manuscript and helpful discussions.

1. Staal, S.P. 1987. Molecular cloning of the akt oncogene and its human homologues AKT1 and AKT2: amplification of AKT1 in a primary human gastric adenocarcinoma. Proc. Natl. Acad. Sci. U. S. A. 84:5034-5037.

2. Staal, S.P., Hartley, J.W., and Rowe, W.P. 1977. Isolation of transforming murine leukemia viruses from mice with a high incidence of spontaneous lymphoma. Proc. Natl. Acad. Sci. U. S. A. 74:3065-3067.

3. Vanhaesebroeck, B., and Alessi, D.R. 2000. The PI3K-PDK1 connection: more than just a road to PKB. Biochem. J. 346:561-576.

4. Altomare, D.A., et al. 1995. Cloning, chromosomal localization and expression analysis of the mouse Akt2 oncogene. Oncogene. 11:1055-1060.

5. Altomare, D.A., Lyons, G.E., Mitsuuchi, Y., Cheng, J.Q., and Testa, J.R. 1998. Akt2 mRNA is highly expressed in embryonic brown fat and the AKT2 kinase is activated by insulin. Oncogene. 16:2407-2411.

6. Brodbeck, D., Cron, P., and Hemmings, B.A. 1999. A human protein kinase $B \gamma$ with regulatory phosphorylation sites in the activation loop and in the C-terminal hydrophobic domain. J. Biol. Chem. 274:9133-9136.

7. Nakatani, K., Sakaue, H., Thompson, D.A., Weigel, R.J., and Roth, R.A. 1999. Identification of a human Akt3 (protein kinase B $\gamma$ ) which contains the regulatory serine phosphorylation site. Biochem. Biophys. Res. Comm. 257:906-910.

8. Coffer, P.J., Jin, J., and Woodgett, J.R. 1998. Protein kinase B (c-Akt): a multifunctional mediator of phosphatidylinositol 3-kinase activation. Biochem. J. 335:1-13.

9. Brazil, D.P., and Hemmings, B.A. 2001. Ten years of protein kinase B signalling: a hard Akt to follow. Trends Biochem. Sci. 26:657-664.

10. Hemmings, B.A. 1997. Akt signaling: linking membrane events to life and death decisions. Science. 275:628-630.

11. Franke, T.F., et al. 1995 . The protein kinase encoded by the Akt protooncogene is a target of the PDGF-activated phosphatidylinositol 3-kinase. Cell. 81:727-736.

12. Burgering, B.M.T., and Coffer, P.J. 1995. Protein kinase B (c-Akt) in phosphatidylinositol-3-OH kinase signal transduction. Nature. 376:599-602.

13. Cohen, P., Alessi, D.R., and Cross, D.A.E. 1997. PDK1, one of the missing links in insulin signal transduction? FEBS Lett. 410:3-10.

14. Walker, K., et al. 1998. Activation of protein kinase $B \beta$ and $\gamma$ isoforms by insulin in vivo and by 3 -phosphoinositide-dependent protein kinase- 1 in vitro: comparison with protein kinase B $\alpha$. Biochem. J. 331:299-308.

15. Verdu, J., Buratovich, M.A., Wilder, E.L., and Birnbaum, M.J. 1999. Cellautonomous regulation of cell and organ growth in Drosophila by Akt/PKB. Nat. Cell Biol. 1:500-506.

16. Tuttle, R.L., et al. 2001. Regulation of pancreatic $\beta$-cell growth and survival by the serine/threonine protein kinase Akt1/PKB $\alpha$. Nat. Med. 7:1133-1137.

17. Bernal-Mizrachi, E., Wen, W., Stahlhut, S., Welling, C.M., and Permutt, M.A. 2001. Islet $\beta$-cell expression of constitutively active Akt $1 / \mathrm{PKB} \alpha$ induces striking hypertophy, hyperplasia, and hyperinsulinemia. J. Clin. Invest. 108:1631-1638. doi:10.1172/JCI200113785.

18. Kohn, A.D., et al. 1998. Construction and characterization of a conditionally active version of the serine/threonine kinase Akt. J. Biol. Chem. 273:11937-11943.

19. Barthel, A., et al. 1999. Regulation of GLUT1 gene transcription by the serine/threonine kinase Akt1. J. Biol. Chem. 274:20281-20286. 
20. Cross, D.A.E., et al. 1997. Insulin activates protein kinase B, inhibits glycogen synthase kinase-3 and activates glycogen synthase by rapamycin-insensitive pathways in skeletal muscle and adipose tissue. FEBS Lett. 406:211-215.

21. Takata, M., et al. 1999. Requirement for Akt (protein kinase B) in insulininduced activation of glycogen synthase and phosphorylation of 4E-BP1 (PHAS-1). J. Biol. Chem. 274:20611-20618.

22. Garofalo, R. 2002. Genetic analysis of insulin signaling in Drosophila. Trends Endocrinol. Metab. 13:156-162.

23. Chen, W., et al. 2001. Growth retardation and increased apoptosis in mice with homozygous disruption of the akt 1 gene. Genes Dev. 15:2203-2208.

24. Cho, H., Thorvaldsen, J., Chu, Q., Feng, F., and Birnbaum, M. 2001. Akt $1 / \mathrm{PKB} \alpha$ is required for normal growth but dispensable for maintenance of glucose homeostasis in mice. J. Biol. Chem. 276:38349-38352.

25. Cho, H., et al. 2001. Insulin resistance and a diabetes mellitus-like syndrome in mice lacking the protein kinase Akt2 (PKB $\beta)$. Science. 292:1728-1731.

26. Reitman, M., Arioglu, E., Gavrilova, O., and Taylor, S. 2000. Lipoatrophy revisited. Trends Endocrinol. Metab. 11:410-416.

27. Roach, M.R., Stock, J.L., Byrum, R., Koller, B.H., and McNeish, J.D. 1995. A new embryonic stem cell line from DBA/1lacJ mice allows genetic modification in a murine model of human inflammation. Exp. Cell Res. 221:520-525.

28. Stewart, C.L. 1993. Production of chimeras between embryonic stem cells and embryos. Methods Enzymol. 225:823-854.

29. Naggert, J.K., Mu, J.L., Frankel, W., Bailey, D.W., and Paigen, B. 1995. Genomic analysis of the $\mathrm{C} 57 \mathrm{Bl} / \mathrm{Ks}$ mouse strain. Mamm. Genome. 6:131-133.

30. Coleman, D.L., and Hummel, K.P. 1973. The influence of genetic background on the expression of the obese $(o b)$ gene in the mouse. Diabetologia. 9:287-293

31. Chua, S.J., et al. 2002. Differential beta cell responses to hyperglycemia and insulin resistance in two novel congenic strains of diabetes (FVBLepr $\left.{ }^{d b}\right)$ and obese (DBA-Lep ${ }^{o b}$ ) mice. Diabetologia. 45:976-990.

32. www.informatics.jax.org/external/festing/mouse/docs/DBA.shtml.

33. Hildebrandt, A.L., Kelly-Sullivan, D.M., and Black, S.C. 2002. Validation of a high resolution X-ray computed tomography system to measure murine adipose tissue depot mass in situ and longitudinally. J. Pharmacol. Toxicol. Methods. 47:99-106.

34. Livak, K.J., and Schmittgen, T.D. 2001. Analysis of relative gene expression data using real-time quantitative PCR and the $2^{-\Delta \Delta C t}$ method. Methods. 25:402-408.

35. Guinovart, J.J., et al. 1979. Glycogen synthase: a new activity ratio assay expressing a high sensitivity to the phosphorylation state. FEBS Lett. 106:284-288.

36. Etgen, G.J., Zavadoski, W.J., Holman, G.D., and Gibbs, E.M. 1999. Insulin-sensitive regulation of glucose transport and GLUT4 translocation in skeletal muscle of GLUT1 transgenic mice. Biochem. J. 337:51-57.

37. Simmons, R.A., Templeton, L.J., and Gertz, S.J. 2001. Intrauterine growth retardation leads to the development of type 2 diabetes in the rat. Diabetes. 50:2279-2286

38. Garofano, A., Czernichow, P., and Breant, B. 2000. Impaired beta-cell regeneration in perinatally malnourished rats: a study with STZ. FASEB J. 14:2611-2617.

39. Nakae, J., Kido, Y., and Accili, D. 2001. Distinct and overlapping functions of insulin and IGF-1 receptors. Endocr. Rev. 22:818-835.

40. Withers, D., et al. 1998. Disruption of IRS- 2 causes type 2 diabetes in mice. Nature 391:900-904

41. Kido, Y., Philippe, N., Schaeffer, A.A., and Accili, D. 2000. Genetic modifiers of the insulin resistance phenotype in mice. Diabetes. 49:589-596.

42. Kubota, N., et al. 2000. Disruption of insulin receptor substrate 2 causes type 2 diabetes because of liver insulin resistance and lack of compensatory $\beta$-cell hyperplasia. Diabetes. 49:1880-1889.

43. Mauvais-Jarvis, F., and Kahn, C.R. 2000. Understanding the pathogenesis and treatment of insulin resistance and type 2 diabetes mellitus: what can we learn from knockout mice? Diabetes Metab. 26:433-448.

44. Peng, X., et al. 2003. Dwarfism, impaired skin development, delayed bone development, inhibition of adipogenesis and skeletal muscle atrophy in mice lacking Akt1 and Akt2. Genes Dev. 17:1352-1365.

45. Magun, R., et al. 1996. Expression of a constitutively activated form of protein kinase B (c-Akt) in 3T3-L1 preadipose cells causes spontaneous differentiation. Endocrinology. 137:3590-3593.

46. Reusch, J.E.B., and Klemm, D.J. 2002. Inhibition of cAMP-response element-binding protein activity decreases protein kinase B/Akt expression in 3T3-L1 adipocytes and induces apoptosis. J. Biol. Chem. 277:1426-1432.

47. Bluher, M., et al. 2002. Adipose tissue selective insulin receptor knockout protects against obesity and obesity-related glucose intolerance. Dev. Cell. 3:25-38.

48. Poy, M.N., et al. 2002. CEACAM1 regulates insulin clearance in liver. Nat. Genet. 30:270-276.

49. Bonner-Weir, S. 2000. Islet growth and development in the adult. J. Mol. Endocrinol. 24:297-302.

50. Kido, Y., et al. 2000. Tissue-specific insulin resistance in mice with mutations in the insulin receptor, IRS-1 and IRS-2. J. Clin. Invest. 105:199-205.

51. Michael, M.D., et al. 2000. Loss of insulin signaling in hepatocytes leads to severe insulin resistance and progressive hepatic dysfunction. Mol. Cell. 6:87-97.

52. Bruning, J.C., et al. 1997. Development of a novel polygenic model of NIDDM in mice heterozygous for IR and IRS-1 null alleles. Cell. 88:561-572.

53. Donath, M.Y., Gross, D.J., Cerasi, E., and Kaiser, N. 1999. Hyperglycemiainduced $\beta$-cell apoptosis in pancreatic islets of Psammomys obesus during development of diabetes. Diabetes. 48:738-744.

54. Pick, A., et al. 1998. Role of apoptosis in failure of $\beta$-cell mass compensation for insulin resistance and $\beta$-cell defects in the male Zucker diabetic fatty rat. Diabetes. 47:358-364.

55 . Withers, D.J., et al. 1999. IRS- 2 coordinates IGF-1 receptor-mediated $\beta$-cell development and peripheral insulin signalling. Nat. Genet. 23:32-40.

56. Lawlor, D.A., Ebrahim, S., and Davey Smith, G. 2002. The association between components of adult height and type II diabetes and insulin resistance: British Women's Heart and Health Study. Diabetologia. 45:1097-1106.

57. Riste, L., Khan, F., and Cruickshank, K. 2001. High prevalence of type 2 diabetes in all ethnic groups, including Europeans, in a British inner city. Diabetes Care. 24:1377-1383

58. Kousta, E., et al. 2000. Women with a history of gestational diabetes of European and South Asian origin are shorter than women with normal glucose tolerance in pregnancy. Diabet. Med. 17:792-797.

59. Brown, D.C., et al. 1991. Height and glucose tolerance in adult subjects. Diabetologia. 34:531-533

60. Etgen, G.J., and Oldham, B.A. 2000. Profiling of Zucker diabetic fatty rats in their progression to the overt diabetic state. Metabolism. 49:684-688.

61. Taylor, S.I. 1999. Deconstructing type 2 diabetes. Cell. 97:9-12.

62. Shimabukuro, M., Zhou, Y.-T., Levi, M., and Unger, R.H. 1998. Fatty acid-induced $\beta$ cell apoptosis: a link between obesity and diabetes. Proc. Natl. Acad. Sci. U. S. A. 95:2498-2502.

63. Kitamura, T., Nakae, J., Biggs, W.H., III, White, M.F., and Accili, D. 2001. The transcription factor FKHR promotes $\beta$ cell survival in IRS- 2 knockout mice. International Symposium on Insulin Receptors and Insulin Action, 8th. Geneva, Switzerland. (Abstr.)

64. Brunet, A., et al. 1999. Akt promotes cell survival by phosphorylating and inhibiting a Forkhead transcription factor. Cell. 96:857-868. 